
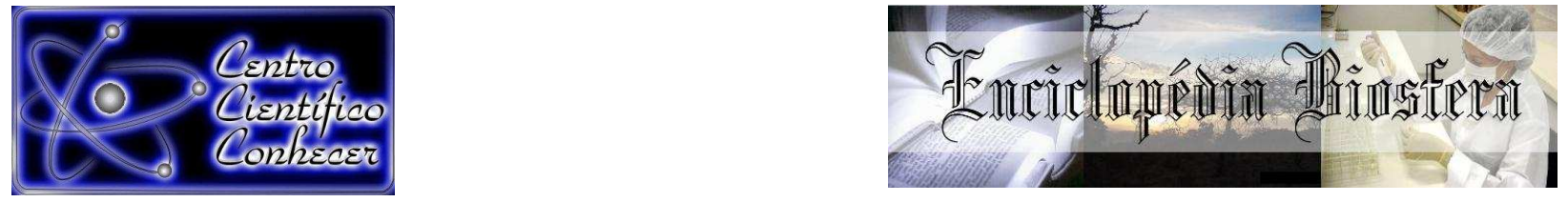

\title{
O ÁCIDO INDOLBUTÍRICO (IBA) É VIÁVEL PARA A SOBREVIVÊNCIA E O ENRAIZAMENTO DE MINIESTACAS DE Eucalyptus dunnii?
}

\author{
Ana Claudia Spassin ${ }^{1}$, Flávio Augusto de Oliveira Garcia ${ }^{2}$ \\ ${ }^{1}$ Doutoranda do Programa de Pós-Graduação em Ciências Florestais da \\ Universidade Estadual do Centro-Oeste - UNICENTRO \\ (anaspassin@yahoo.com.br), Irati, PR, Brasil. \\ ${ }^{2}$ Professor Doutor do Departamento de Engenharia Florestal da Universidade \\ Estadual do Centro-Oeste - UNICENTRO, Irati, PR, Brasil. \\ Recebido em: 08/04/2016 - Aprovado em: 30/05/2016 - Publicado em: 20/06/2016 \\ DOI: 10.18677/Enciclopedia_Biosfera_2016_072
}

\begin{abstract}
RESUMO
A cultura do eucalipto apresenta grande importância para o setor florestal e para a economia brasileira. Na região Sul, uma das principais espécies recomendadas para - plantio é o Eucalyptus dunnii. A capacidade de resistir a geadas severas associadas à qualidade da madeira torna o plantio da espécie desejável, mas a baixa produção de sementes e o baixo percentual de enraizamento das miniestacas dificultam a propagação vegetativa da espécie. Desta forma, objetivou-se estimar o efeito da aplicação da auxina sintética (IBA) na sobrevivência e enraizamento de miniestacas de E. dunnii. As miniestacas foram coletadas de minicepas de origem seminal e confeccionadas com dimensões entre 4 a $6 \mathrm{~cm}$, deixando-se dois pares de folhas. Para o enraizamento, a porção basal da miniestaca foi imersa em cinco concentrações de IBA $\left(0,1000,2000,3000\right.$ e $\left.4000 \mathrm{mg} \mathrm{L}^{-1}\right)$ durante 10 segundos. $O$ delineamento utilizado foi 0 inteiramente casualizado com quatro repetições contendo 10 miniestacas por repetição. Avaliou-se a sobrevivência, o enraizamento, o comprimento total do sistema radicular e altura das miniestacas. Com base nos resultados, conclui-se que nas condições em que o estudo foi realizado a aplicação do IBA não teve efeito sobre a sobrevivência e enraizamento das miniestacas de $E$. dunnii, portanto, o ácido indolbutírico não deve ser usado como fator de estímulo ao enraizamento e sobrevivência de miniestacas desta espécie.
\end{abstract}

PALAVRAS-CHAVE: auxina, miniestaquia, propagação vegetativa

\section{EFFECT OF INDOLBUTYRIC ACID (IBA) ON THE SURVIVAL AND ROOTING OF MINICUTTINGS OF EUCALYPTUS DUNNII}

\begin{abstract}
The cultivation of eucalyptus trees plays an important role inBrazilian forest sector and economy. In the region south, one of the main species recommended for planting is the Eucalyptus dunnii. The ability to withstand severe frosts associated with wood quality make the planting of desirable species, but the low seed production and the low percentage of rooting of minicuttings hampers the vegetative propagation of the species. The aim of this study was to estimate the effect of the application of the synthetic auxin (IBA) on the survival and rooting of minicuttings of $E$. dunnii. The minicuttings were collected from ministumps originated from seedlings and prepared
\end{abstract}


whit size between 4 the $6 \mathrm{~cm}$, with two leaf pairs. For rooting, the minicutting basal portion was plungeg in five concentration of IBA $(0,1000,2000,3000$ and $4000 \mathrm{mg}$ $\left.\mathrm{L}^{-1}\right)$ for 10 seconds. The experimental design was completely randomized with four replicates and 10 minicuttings per replicate.Was evaluated the survival, rooting, the total length of the root system and height minicuttings. Basead on the results, it is concluded that the conditions in which the study was conducted application the IBA had no effect on survival and rooting of the minicuttings of Eucalyptus dunnii, therefore, the IBA should not be used as a stimulating factor rooting and survival of minicuttings of this species.

KEYWORDS: Auxin, minicuttings technique, vegetative propagation

\section{INTRODUÇÃO}

A propagação vegetativa de Eucalyptus spp. no Brasil, em escala comercial, teve início com a técnica de estaquia convencional, implementada no final da década de 70 , do século XX. Esta técnica representou um marco para o setor florestal, principalmente, pois seu uso permitiu melhorias na homogeneidade das florestas e facilitou a propagação de materiais superiores (ALFENAS et al., 2009). No entanto, a ocorrência de alguns fatores limitantes, como o baixo percentual de enraizamento implicou na necessidade de alterações e/ou complementações no processo de clonagem vegetal (SANTOS et al., 2005).

Com o aprimoramento da técnica de estaquia convencional, a miniestaquia é a técnica mais utilizada pela maioria das empresas florestais que utilizam a propagação clonal de espécies de Eucalyptus (ALFENAS et al., 2009). Esta técnica permitiu a otimização do processo de enraizamento e qualidade da muda clonal, principalmente de clones que apresentavam maior dificuldade de enraizamento (XAVIER et al., 2009).

$\mathrm{Na}$ região Sul do Brasil tem-se no fenômeno da geada em algumas localidades. Isto é considerado um limitador para a propagação de algumas procedências tropicais de Eucalyptus spp., sobretudo de híbridos de $E$. urophylla $\mathrm{x}$ $E$. grandis. Deste modo um grupo muito restrito de espécies constituem aquelas com potencialidades para o uso nestas situações, destacando-se E. benthamii, E. dunnii e E. viminalis (PALUDZYSZYN FILHO et al., 2006).

A espécie $E$. dunnii é de reconhecida importância para regiões de geadas no Sul do Brasil, porém apresenta limitações como baixa produção e custo elevado de sementes (GRAÇA, 1987) e baixo percentual de enraizamento de estacas. Logo o conhecimento de fatores que influenciam no enraizamento de brotações é essencial para o sucesso da propagação clonal da espécie. Em geral, assume-se a partir de resultados obtidos na literatura, que espécies de Eucalyptus resistentes ao frio apresentam maior recalcitrância ao enraizamento se comparadas às não resistentes (BRONDANI et al., 2014). Assim, para espécies de difícil enraizamento, a aplicação de um fitoregulador pode compensar a falta de auxina endógena na planta.

Dentre os grupos de reguladores de crescimento mais utilizados na propagação vegetativa de plantas, destacam-se as auxinas (GOULART et al., 2008). Este fitorregulador desempenha papel preponderante na promoção e na formação de raízes adventícias de diversas espécies vegetais (GOULART et al., 2011), todavia podem ter efeito variável dependendo da espécie utilizada e local de aplicação.

Dentre as auxinas sintéticas mais conhecidas e utilizadas no enraizamento de estacas, o ácido indolbultírico (IBA) é o mais adotado (VILLA et al., 2003). Relata-se o uso deste regulador em diferentes culturas, principalmente aquelas que 
apresentam dificuldade em emitir raízes (VERNIER \& CARDOSO, 2013); incluindose diferentes espécies de Eucalyptus (GOULART et al., 2011).

Pouco ainda se conhece sobre a aplicação de auxinas sintéticas em miniestacas de E. dunnii. Em estudo in vitro, GRAÇA (1997) relatou que o uso de Ácido Indol-acético - AIA em altas concentrações estimulou o enraizamento de brotações de alguns clones de $E$. dunnii. Contudo em condições ex vitro não há relatos do uso deste regulador do crescimento.

Diante do exposto, objetivou-se estimar o efeito de auxina sintética (IBA) no enraizamento e sobrevivência de miniestacas de $E$. dunnii.

\section{MATERIAL E MÉTODOS}

As miniestacas de $E$. dunnii foram coletadas em um minijardim clonal de aproximadamente dois anos de idade, formado a partir de mudas seminais. Para a formação das brotações, as minicepas foram adubadas duas vezes por semana com nutrição mineral balanceada, de modo a se obter um bom padrão de vigor do minijardim e posteriormente das miniestacas (ALFENAS et al., 2009).

Inicialmente, as miniestacas foram coletadas utilizando-se uma tesoura de poda previamente lavada e desinfestada em álcool $70 \%(\mathrm{v} / \mathrm{v})$ por 30 segundos, sendo confeccionadas utilizando a parte apical, com dimensões entre 4 a $6 \mathrm{~cm}$ de comprimento, mantendo-se entre dois a três pares de folhas reduzidas à metade de seu tamanho original. Após a coleta, as miniestacas foram levadas até a casa de vegetação, imergindo-as por 10 segundos em solução hidroalcoólica de diferentes concentrações de Ácido Indol-butírico - IBA (auxina sintética) e imediatamente colocadas para enraizamento em tubetes de plásticos de $110 \mathrm{~cm}^{3}$, contendo substrato Macplant.

As miniestacas foram coletadas no período matutino, a fim de evitar a evapotranspiração excessiva das estruturas e desta forma minimizar o estresse hídrico dos propágulos selecionados. Para manter as condições de turgescência do material vegetativo, as miniestacas, após a coleta foram acondicionadas em caixas de isopor com água gelada até o início da aplicação dos tratamentos. O período compreendido entre a coleta das miniestacas, seu preparo e estaqueamento foi inferior a 30 minutos.

Buscando avaliar o efeito do regulador de crescimento no enraizamento das miniestacas, foram preparadas e testadas cinco concentrações $(0,1.000,2.000$, 3.000 e $4.000 \mathrm{mg} \mathrm{L}^{-1}$ ) de ácido IBA. Para o preparo da solução hidroalcóolica de IBA, inicialmente pesou-se 0,$1 ; 0,2 ; 0,3$ e $0,4 \mathrm{~g}$ de IBA em balança analítica, diluindo-se em $50 \mathrm{~mL}$ de álcool em um Becker. Após diluição do IBA completou-se o volume da solução para $100 \mathrm{~mL}$ com água destilada, obtendo-se as concentrações citadas.

As bandejas com as miniestacas foram colocadas em casa de vegetação climatizada (umidade relativa do ar $>80 \%$ e temperatura $25^{\circ} \mathrm{C} \pm 2$ ) com permanência de 25 dias. Em seguida, as miniestacas foram transferidas para a casa de sombra, permanecendo por 20 dias e finalmente, levadas para rustificação a sol até os 70 dias após estaqueamento - DAE.

Avaliou-se a sobrevivência (\%) das miniestacas na saída da casa de vegetação, na casa de sombra e na área de pleno sol. Após 70 dias de permanência das miniestacas no substrato, avaliou-se o total de miniestacas enraizadas (\%). Destas, foi mensurada a altura $(\mathrm{cm})$ e o comprimento total de raízes $(\mathrm{cm})$ emitidas por muda formada. 
Como miniestacas vivas consideraram-se aquelas que apresentaram a coloração verde, e como miniestacas enraizadas consideraram-se todas aquelas que apresentaram, pelo menos, uma raiz visível.

O experimento foi conduzido no delineamento inteiramente casualizado, com cinco tratamentos constituídos por quatro repetições de 10 miniestacas cada. A partir dos dados obtidos, realizou-se a análise de variância e ajuste de regressões polinomiais.

\section{RESULTADOS E DISCUSSÃO}

Houve efeito das diferentes doses de IBA $(p<0,05)$ em relação à na sobrevivência das miniestacas de $E$. dunnii na saída da área de pleno sol - SOBPL (Tabela 1). Contudo, não foi constatado efeito entre as diferentes doses de IBA em relação à sobrevivência das miniestacas na saída da casa de vegetação - SOBCV, saída da casa de sombra - SOBCS, enraizamento - ENR, comprimento total do sistema radicular - CTSR e altura - ALT das miniestacas na saída da área de pleno sol (Tabela 1).

TABELA 1 - Análise de variância referente à sobrevivência das miniestacas de $E$. dunnii na saída da casa de vegetação (SOBCV), saída da casa de sombra (SOBCS), saída da área de pleno sol (SOBPL), enraizamento (ENR), comprimento total do sistema radicular (CTSR) e altura (ALT) aos 70 dias de idade, sob diferentes concentrações de IBA.

\begin{tabular}{cccccccc}
\hline & & \multicolumn{7}{c}{ Teste F } \\
\cline { 3 - 7 } FV & GL & SOBCV & SOBCS & SOBPL & ENR & CTSR & Alt \\
\hline$($ IBA $)$ & 4 & $2,28^{\text {ns }}$ & $0,72^{\text {ns }}$ & $4,15^{*}$ & $0,49^{\text {ns }}$ & $0,48^{\text {ns }}$ & \\
& & & & & & & $2,12^{\text {ns }}$ \\
Média & - & 90,5 & 44,0 & 29,0 & 8,0 & 11,56 & 8,56 \\
\hline * & & & & & & &
\end{tabular}

* significativo ao nível de $5 \%$ de probabilidade de erro, pelo teste $\mathrm{F}$. ${ }^{\text {ns }}$ valor não significativo ao nível de $5 \%$ de probabilidade de erro, pelo teste $\mathrm{F}$. FV = Fonte de variação. $\mathrm{GL}=$ graus de liberdade.

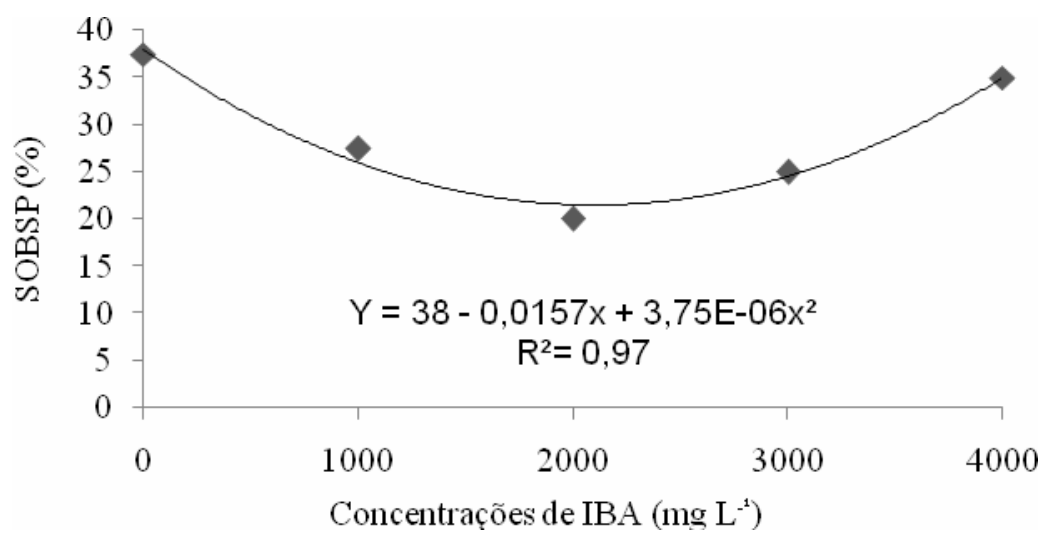

FIGURA 1 - Sobrevivência das miniestacas de E. dunnii na saída da área de pleno sol (SOBPL), aos 70 dias de idade, em resposta a aplicação de diferentes concentrações de IBA (0, 1000, 2000, 3000 e 4000 mg $\left.\mathrm{L}^{-1}\right)$.

$\mathrm{Na}$ saída da casa de vegetação as miniestacas apresentaram sobrevivência em relação às concentrações de IBA testadas de 95\%, 82,5\%, 82,5\%, 97\% e 95\% 
respectivamente para as doses de $0,1000,2000,3000$ e $4000 \mathrm{mgL}^{-1}$. Não houve diferença entre estas doses (Tabela 1). Esses resultados assemelham-se aos encontrados para diferentes espécies de Eucalyptus, como: E. globulus (BORGES et al., 2011), híbridos de E. benthamii x E. dunnii (BRONDANI et al., 2010) e E. grandis (WENDLING \& XAVIER, 2005), em que os autores constataram alta sobrevivência das miniestacas nessa fase.

O alto percentual de sobrevivência das miniestacas obtidos nesta etapa indica as boas condições de controle ambiental (temperatura e umidade) encontradas no interior da casa de vegetação. Segundo WENDLING \& XAVIER (2005), o bom manejo do ambiente é fundamental para a manutenção e sobrevivências das miniestacas neste ambiente. Os mesmos autores afirmam que quando esta premissa é atendida obtém-se sobrevivência elevada das miniestacas na casa de vegetação, sendo difícil observar grandes diferenças na sobrevivência dos propágulos vegetativos.

Ao saírem da casa de vegetação houve uma alteração na sobrevivência das mudas, observando-se aumento da mortalidade na fase de aclimatização em casa de sombra. Embora o percentual de SOBCS (sobrevivência na saída da casa de sombra) tenha sido menor que a SOBCV (sobrevivência na saída da de vegetação), não houve diferença entre os tratamentos. A SOBCS foi de $50 \%$ para os tratamentos 3000 e $4000 \mathrm{mgL}^{-1}$, de $42,5 \%$ para os tratamentos 0 e $1000 \mathrm{mg} \mathrm{L}^{-1}$ e de $35 \%$ para 0 tratamento $2000 \mathrm{mg} \mathrm{L}^{-1}$ de IBA.

A redução nos índices de sobrevivência observada durante a saída da casa de sombra é fato relatado por outros autores. WENDLING \& XAVIER (2005) atribuem tal comportamento aos maiores efeitos de estresse hídrico e de iluminação encontradas nesta área de aclimatização. Além disso, BRONDANI et al. (2014) relatam que esta redução na sobrevivência entre a casa de vegetação e casa de sombra parece normal para as espécies subtropicais de Eucalyptus as quais apresentam recalcitrância ao enraizamento e portanto a não formação de raiz na etapa inicial que resulta na redução da sobrevivência na área de aclimatização.

Assim acredita-se que tenha ocorrido fato similar, em que mesmo tendo saído "vivas" da casa de vegetação as miniestacas morreram na fase subsequente pela ausência de raízes. Por outro lado, durante a avaliação de SOBPL constatou-se efeito nas doses de IBA testadas. Os resultados da sobrevivência indicaram resposta quadrática em função do aumento das concentrações de IBA (Figura 1), indicando que, à medida que se aumentam as doses do fitoregulador, a tendência é ocorrer o aumento na mortalidade das miniestacas até uma dose intermediária, ocorrendo aumento da sobrevivência com o uso de doses mais elevadas.

As miniestacas que não foram tratadas com o IBA apresentaram os maiores percentuais de sobrevivência (37,5\%). As miniestacas tratadas com as doses 1000 e $2000 \mathrm{mg} \mathrm{L}^{-1}$ tiveram 27,5 e $20 \%$ de sobrevivência, respectivamente. Ressalta-se que na curva de sobrevivência a região do tratamento $2000 \mathrm{mg} \mathrm{L}^{-1}$ encontra-se próximo ao ponto de inflexão da curva. Logo os tratamentos 3000 e $4000 \mathrm{mg} \mathrm{L}^{-1}$ tiveram sobrevivência mais elevada que o tratamento $2000 \mathrm{mg} \mathrm{L}^{-1}$, sendo de $25 \%$ para 0 tratamento $3000 \mathrm{mg} \mathrm{L}^{-1} \mathrm{e} 35 \%$ para o tratamento $4000 \mathrm{mg} \mathrm{L}^{-1}$ (Figura 1). O efeito quadrático não é um efeito desejado, pois no caso do presente estudo é possível observar que a não utilização da auxina exógena foi o melhor tratamento em relação à sobrevivência das miniestacas. Estudos com outros reguladores de crescimento como: brassinosteroides, ácido jasmônico e ácido salicílico podem ajudar no processo de indução e formação de raízes desta espécie, pois podem ser mitigadores de estresse. 
Foi verificado na avaliação do enraizamento das miniestacas, que, os resultados do enraizamento indicaram resposta cúbica em função do aumento das concentrações de IBA (Figura 2). O uso do IBA proporcionou menor percentual de miniestacas enraizadas, até uma dose média $\left(2000 \mathrm{mg} \mathrm{L}^{-1}\right)$, a partir do aumento das doses ocorreu um pequeno aumento no percentual de miniestacas enraizadas.

As miniestacas que não foram tratadas com o IBA apresentaram o maior percentual de enraizamento (15\%), sendo observada redução no percentual de miniestacas enraizadas com o uso das doses de 1000 e $2000 \mathrm{mg} \mathrm{L}^{-1}(5 \%)$, e pequeno aumento no enraizamento nas doses de 3000 e $4000 \mathrm{mg} \mathrm{L}^{-1}(7,5 \%)$. Contudo, não foram observadas diferenças no enraizamento das miniestacas de $E$. dunnii tratadas com diferentes concentrações do IBA, obtendo-se em média $8 \%$ de miniestacas enraizadas.

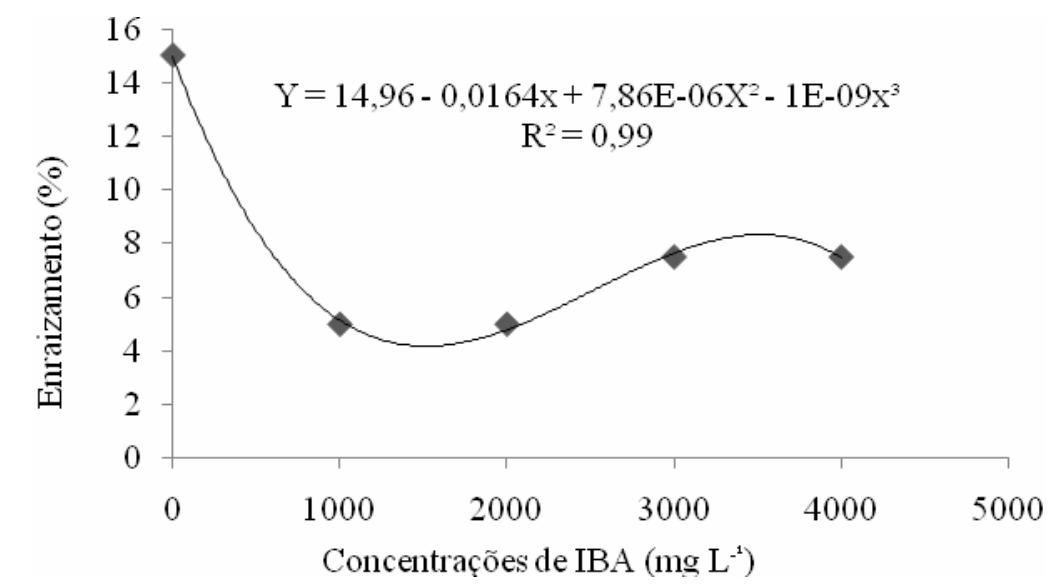

FIGURA 2 - Enraizamento das miniestacas de E. dunnii (ENR) aos 70 dias de idade, em resposta a aplicação de diferentes concentrações de IBA $\left(0,1000,2000,3000\right.$ e $\left.4000 \mathrm{mg} \mathrm{L}^{-1}\right)$.

O baixo percentual de miniestacas de Eucalyptus sp. Enraizadas, utilizando a técnica de miniestaquia e fazendo-se do uso de IBA, não é comum. Na literatura existem trabalhos que relatam o efeito positivo da miniestaquia associado ao uso de fitoregulador (TITON et al., 2003; GOULART et al., 2008). Contudo resultados de baixos percentuais de enraizamento fazendo-se o uso de fitoregulador, já foram observados por outros autores. BRONDANI et al. (2014) observaram que nas estações mais quentes a mortalidade de miniestacas de $E$. benthamii chegou a ser superior a $80 \%$, ocasionando desta forma um número reduzido de miniestacas enraizadas. Comportamento semelhante também foi observado por BRONDANI et al. (2010) que, trabalhando com híbridos de E. benthamii x E. dunnii, observaram que os resultados do enraizamento foram menores que $10 \%$ nas estações quentes (primavera e verão).

A recalcitrância ao enraizamento que espécies de clima subtropical possuem, é um fator que ajuda a explicar os baixos percentuais de miniestacas enraizadas neste estudo. Além disso, a época do ano em que o estudo foi realizado pode ter contribuído para que os índices de enraizamento fossem baixos.

Segundo BRONDANI et al. (2010), os baixos índices de enraizamento observados neste estudo e em estudos com espécies de Eucalyptus recomendadas para o plantio em regiões subtropicais, possivelmente ocorre, devido à elevada 
recalcitrância aos processos de enraizamento que as espécies de clima frio possuem (E. dunnii, E. benthamii, E. viminalis) quando comparadas com as espécies de clima tropical (E. grandis, E. urophylla, E. urograndis) que tem como característica alta capacidade de enraizamento. O histórico de recalcitrância ao enraizamento relatado na literatura e observado neste estudo, característico das espécies subtropicais, acabam por vez dificultando a propagação vegetativa destas espécies.

Além da dificuldade de enraizamento característico da espécie de $E$. dunnii, outro fator, como o período em que o estudo foi realizado pode ter contribuído para os baixos índices de enraizamento observados. Segundo ZANG et al. (2013) as condições ambientais (temperatura e umidade relativa do ar) são fatores importantes à propagação vegetativa via estaquia. Embora, temperaturas elevadas possam estimular a diferenciação das células e o desenvolvimento das raízes, este pode também favorecer a perda de água pelas folhas e dificultar o processo de enraizamento adventício.

De acordo com CORRÊA \& FETT-NETO (2004), a temperatura ótima para o enraizamento adventício varia entre gêneros e entre espécies de um mesmo gênero, sendo que altas temperaturas favorecem o enraizamento de espécies de clima tropical e baixas temperaturas favorecem o enraizamento de espécie de clima subtropical.

Como já relatado, a aplicação do fitoregulador não influenciou no processo de indução de formação de raízes e no desenvolvimento do sistema radicular das miniestacas, contudo, vale ressaltar que o uso do fitoregulador não causou efeitos tóxicos as miniestacas, como já relatado por outros autores. $O$ efeito de toxicidade na planta pode ser observado por meio da redução do número de miniestacas enraizadas ou aumento de miniestacas mortas na medida em que ocorre o aumento da concentração do regulador utilizado, como observado em estudo realizado por OLIVEIRA et al. (2015).

Concordando com os resultados deste estudo, WENDLING \& XAVIER (2005) verificaram que a aplicação de IBA não resultou em aumento na sobrevivência e enraizamento das miniestacas de diferentes clones de E. grandis, contudo, os autores constataram certos níveis de toxidez nas doses acima de $500 \mathrm{mg} \mathrm{L}^{-1}$ para algumas características e clones avaliados no estudo.

$\mathrm{Na}$ literatura, existe relato de que a aplicação de IBA pode promover resultados positivos para o enraizamento de espécies arbustivas e lenhosas (TAKATA et al., 2012; PAULUS et al., 2014; CAMPOS et al., 2015), e em materiais que apresentam recalcitrância ao enraizamento. Trabalhando com espécies do gênero Eucalyptus consideradas de difícil enraizamento, BRONDANI et al. (2010) concluíram que o uso do fitoregulador influenciou positivamente nos processos rizogênicos de hibrido de $E$. benthamii x E. dunni, contudo, os autores observaram que alguns clones apresentavam maior capacidade de enraizamento somente quando as miniestacas eram tratadas com as maiores concentrações do IBA.

BRONDANI et al. (2014) estudaram o efeito de diferentes concentrações de IBA no enraizamento adventício de miniestacas de $E$. benthammi. Os autores concluíram que embora observado baixo percentual de enraizamento, visto que esta é uma espécie considerada de difícil propagação vegetativa, as miniestacas obtidas de minicepas que receberam determinadas soluções nutritivas, associadas à presença da concentração de $2000 \mathrm{mg} \mathrm{L}^{-1}$, foram as que apresentaram os maiores índices de enraizamento. 
Observa-se a partir destes e de alguns outros trabalhos que o efeito do IBA é variável na planta e que este depende de uma série de fatores (BRONDANI et al., 2010). Normalmente, para espécies do gênero Eucalyptus spp. são relatados melhores resultados com concentrações mais baixas do regulador de crescimento (TITON et al., 2003; GOULART et al., 2008) ou com a não aplicação do mesmo (SOUZA JUNIOR \& WENDLING, 2003; WENDLING \& XAVIER, 2005).

$\mathrm{Na}$ avaliação das miniestacas na saída da área de pleno sol, em relação ao regulador de crescimento IBA, novamente não foram observados efeitos nas diferentes concentrações avaliadas, tanto no que diz respeito à característica altura quanto ao comprimento total do sistema radicular das miniestacas aos 70 dias de idade.

A partir dos resultados, observou-se que para a variável altura o maior crescimento médio foi de $11,77 \mathrm{~cm}$ na dose de $3000 \mathrm{mg} \mathrm{L}^{-1}$ e menor crescimento médio de $5 \mathrm{~cm}$ obtido na dose $2000 \mathrm{mgL}^{-1}$, com crescimento médio geral de $8,5 \mathrm{~cm}$ em altura. Embora o crescimento médio em altura tenha apresentado um valor muito abaixo daquele necessário para que uma muda com bom desenvolvimento seja levada a campo, estes resultados são próximos ao encontrados na literatura por TITON et al. (2003) e GOULART et al. (2008), a qual trabalharam com espécies de Eucalyptus que apresentam bom enraizamento quando produzidos pela técnica de miniestaquia.

No que se refere ao comprimento total do sistema radicular, as miniestacas apresentaram o mesmo comportamento observado no crescimento em altura. Observou-se que o maior comprimento do sistema radicular ocorreu na dose 3000 $\mathrm{mg} \mathrm{L}^{-1}$, com crescimento médio de $18,9 \mathrm{~cm}$ e o menor crescimento médio foi observado na dose de $2000 \mathrm{mg} \mathrm{L}^{-1}$, com $6,5 \mathrm{~cm}$ de comprimento. Contudo, como já ressaltado, a aplicação das diferentes concentrações de IBA, não foram significativas para as variáveis, altura e comprimento de raiz.

Esses resultados assemelham-se aos encontrados por TITON et al. (2003), WENDLING \& XAVIER (2005) e GOULART et al. (2008), que ao trabalharem com clones de diferentes espécies de Eucalyptus, não constataram o efeito de diferentes concentrações de IBA no crescimento das miniestacas.

No presente estudo, a sobrevivência e enraizamento das miniestacas de $E$. dunnii não sofreram influencia na presença de diferentes concentrações de IBA. Em estudo semelhante, SOUZA JUNIOR \& WENDLING (2003), concluíram que a técnica de miniestaquia utilizando minicepas de origem seminal é viável, mas que o uso do IBA não é necessário para o processo de enraizamento de miniestacas de $E$. dunnii, visto o alto grau de juvenilidade do material utilizado.

Apesar, dos procedimentos adotados serem semelhantes ao realizados por esses autores, neste estudo, os índices de enraizamento foram baixos. Essa diferença pode estar relacionada aos aspectos envolvendo o manejo adotado nas minicepas e miniestacas da espécie, bem como a variação do clima encontrado em cada local de estudo.

De maneira geral, observou-se neste estudo que o uso do IBA e suas diferentes concentrações testadas, não influenciaram de maneira significativa os aspectos relacionados à produção das mudas de $E$. dunnii. Além disso, os altos índices de sobrevivência obtidos no inicio do processo, não garantiram um alto percentual de sobrevivência e enraizamento das miniestacas aos 70 dias de idade.

Com a grande variabilidade nos resultados de enraizamento relatados para diferentes culturas na literatura, entende-se que o enraizamento adventício de estacas é um processo complexo e que pode sofrer influência de fatores como: 
nutrição mineral (ROCHA et al., 2013; PICOLOTTO et al., 2015) substrato (TIMM et al., 2015), época de coleta (PEÑA et al., 2015; PIRES et al., 2015; OLIVEIRA et al., 2016), tamanho e porção da miniestacas (SOUZA et al., 2013; BATISTA et al., 2014; MORAES et al., 2014; CORREIA et al., 2015), idade das minicepas (SANTOS et al., 2014) e níveis de hormônios endógenos na planta (BOTIN \& CARVALHO, 2015), sendo, fundamental conhecer o modo de ação desses fatores para se obter sucesso no processo enraizamento.

Desta forma, mediante ao baixo percentual de enraizamento e a importância que a espécie apresenta para a região Sul do Brasil, novos estudos relacionados ao uso de outros reguladores de crescimento (brassinosteroides, ácido jasmônico, ácido salićlico) e ao tempo de aclimatação adequado da espécie devem ser realizados. Estudos nesta nova linha de pesquisa podem ajudar a obter resultados satisfatórios no processo de produção e formação de raízes adventícias de E. dunnii utilizando a técnica de miniestaquia.

\section{CONCLUSÃO}

O ácido indolbutírico não deve ser usado como fator de estímulo ao enraizamento e sobrevivência de miniestacas de $E$. dunnii.

\section{AGRADECIMENTOS}

À Coordenação de aperfeiçoamento de pessoal de nível superior - CAPES pela concessão da bolsa de estudos.

\section{REFERÊNCIAS}

ALFENAS, A. C.; ZAUZA, E. A. V.; MAFIA, R. G.; ASSIS, T. F. Clonagem e doenças do eucalipto. Viçosa: Editora UFV, 2009, 500p.

BATISTA, A. F.; SANTOS, G. A.; SILVA, L. D.; QUEVEDO, F. F.; ASSIS, T. F. Influência da arquitetura foliar de miniestacas na propagação clonal de Eucalyptus. Revista Árvore, v. 38, n. 5, p. 819-827, 2014. Disponível em: <http://dx.doi.org/10.1590/S0100-67622014000500006> doi: 10.1590/S010067622014000500006

BORGES, S. R.; XAVIER, A.; OlIVEIRA, L. S.; MELO, L. A.; ROSADO, A. M. Enraizamento de miniestacas de clones híbridos de Eucalyptus globulus. Revista Árvore, v. 35, n. 3, p. $425-434$, 2011. Disponível em: <http://dx.doi.org/10.1590/S0100-67622011000300006>. doi: 10.1590/S010067622011000300006

BOTIN, A. A.; CARVALHO, A. Reguladores de crescimento na produção de mudas florestais. Revista de Ciências agroambientais,. v. 13, n. 1, p. 83-96, 2015.

BRONDANI, G. E.; GROSSI, F.; WENDLING, I.; DUTRA, L. F.; ARAUJO, M. A. Aplicação de IBA para o enraizamento de miniestacas de Eucalyptus benthamii Maiden e Cambage x Eucalyptus dunnii Maiden. Acta Scientiarium Agronomy, v. 32, n. 4, p. $667 \quad-\quad 674, \quad 2010 . \quad$ Disponível em: <http://dx.doi.org/10.4025/actasciagron.v32i4.4879>. doi: 10.4025/actasciagron.v32i4.4879 
BRONDANI, G. E.; BACCARIN, F. J. B.; BERGONCI, T.; GONÇALVES, A. N.; ALMEIDA, M. Miniestaquia de Eucalyptus benthamii: efeito do genótipo, AIB, zinco, boro e coletas de brotações. Cerne, v. 20, n.1, p. 147 - 156, 2014. Disponível em: <http://dx.doi.org/10.1590/S0104-77602014000100018>. doi: 10.1590/S010477602014000100018

CAMPOS, G. N. F.; ARRIEL, E. F.; NOBERTO, M. N. S.; FARIAS JUNIOR, J. A.; SILVA, V. V. M.; FREIRE, A. L. O. Clonagem de Cnidoscolus quercifolius por alporquia. Ciência Florestal, v. 25, n. 3, p. 743-749, 2015. Disponível em: <http://dx.doi.org/10.5902/1980509819677>. doi: 10.5902/1980509819677

CORRÊA, L. R.; FETT-NETO, A. G. Effects of temperature on adventitious root development in microcuttings of Eucalyptus saligna Smith and Eucalyptus globulus labill. Journal of thermal biology, v. 29, n. 6, p. $315-324$, 2004. Disponível em: >http://dx.doi.org/10.1016/j.jtherbio.2004.05.006>.

10.1016/j.jtherbio.2004.05.006

CORREIA, A. C. G.; XAVIER, A.; DIAS, P. C.; TITON, M.; SANTANA, R. C. Redução foliar em miniestacas e microestacas de clones híbridos de Eucalyptus globulus. Revista Árvore, v. 39, n. 2, p. 295-304, 2015. Disponível em: <http://dx.doi.org/10.1590/0100-67622015000200009>. doi: 10.1590/010067622015000200009

CUNHA, A. C. M. C. M.; PAIVA, H. N.; LEITE, H. G.; BARROS, N. F.; LEITE, F. P. Influência do estado nutricional de minicepas no enraizamento de miniestacas de eucalipto. Revista Árvore, v.33, n.4, p.607-615, 2009. Disponível em: <http://dx.doi.org/10.1590/S0100-67622009000400003>. doi: 10.1590/S010067622009000400003

DIAS, P. C.; XAVIER, A.; OlIVEIRA, L. S.; PAIVA, H. N.; CORREIA, A. C. G. Propagação vegetativa de progênies de meios-irmãos de angico-vermelho (Anadenanthera macrocarpa (Benth) Brenan) por miniestaquia. Revista árvore, v. 36, n. 3, p. 389-399, 2012. Disponível em: <http://dx.doi.org/10.1590/S010067622012000300001 >. doi: 10.1590/S0100-67622012000300001

GRAÇA, M. E. C. Avaliação do florescimento e do potencial de produção de sementes de Eucalyptus dunnii MAID. no Brasil. Boletim de Pesquisa Florestal, n. 14, p. $1-12,1987$.

GRAÇA, M. E. C. Enraizamento in vitro de brotações de Eucalyptus dunnii utilizando altas concentrações de auxinas. Embrapa Florestas: Colombo - PR, n. 48, p. 1 - 3, 1997.

GOULART, P. B.; XAVIER, A.; CARDOSO, N. Z. Efeito dos reguladores de crescimento AIB e ANA no enraizamento de miniestacas de clones de Eucalyptus grandis x Eucalyptus urophylla. Revista Árvore, v. 32, n. 6, p. $1051-1058,2008$. Disponível em: <http://dx.doi.org/10.1590/S0100-67622008000600010>. doi: $10.1590 / \mathrm{S} 0100-67622008000600010$ 
GOULART, P. B.; XAVIER, A.; DIAS, J. M. M. Efeito dos cofatores hidroquinona, prolina e triptofano no enraizamento de miniestacas de clones de Eucalyptus grandis x E. urophylla. Revista Árvore, v. 35, n. 5, p. 1017 - 1026, 2011. Disponível em: <http://dx.doi.org/10.1590/S0100-67622011000600007>. doi: 10.1590/S010067622011000600007

MORAES, C. E.; FONSECA, R. C. M.; RUI, M. Influência das folhas no enraizamento de miniestaca de híbridos de eucalipto. Nucleus, v. 11, n. 1, p. 101- 106 , 2014. Disponível em: <http:dx.doi.org/10.3738/1982.2278.995>. doi: 10.3738/1982.2278.995

OLIVEIRA, T. P. F.; BARROSO, D. G.; LAMÔNICA, K. R.; CARVALHO, V. S.; OLIVEIRA, M. A. Efeito do ácido indol-3-butírico (AIB) no enraizamento de miniestacas de Ipê-roxo (Handroanthus heptaphylus Mattos). Ciência Florestal, v. 25, n. 4, p. 1043 - 1051, 2015. Disponível em: <http://dx.doi.org/10.5902/1980509820666>. doi: 10.5902/1980509820666

OLIVEIRA, T. P. F.; BARROSO, D. G.; LAMÔNICA, K. R.; CARVALHO, G. C. M. W. Aplicação de AIB e tipo de miniestacas na produção de mudas de Handroanthus heptaphyllus Mattos. Ciência Florestal, v. 26, n. 1, p. 299-306, 2016. Disponível em: <http://dx.doi.org/10.5902/1980509821128>. doi: 10.5902/1980509820666

PALUDZYSZYN FILHO, E.; SANTOS, P. E. T.; FERREIRA, C. A. Eucaliptos indicados para plantio no Estado do Paraná. Colombo: Embrapa Florestas, 2006.

PAULUS, D.; VALMORBIDA, R.; TOFFOLI, E.; PAULUS, E. Propagação vegetativa de Aloysia triphylla (L'Hér.) Britton em função da concentração de AIB e do comprimento das estacas. Revista Brasileira de plantas medicinas, v. 16, n. 1, p. 25-31, 2014. Disponível em: <http://dx.doi.org/10.1590/S151605722014000100004>. doi: 10.1590/S1516-05722014000100004

PEÑA, M. L. P.; ZANETTE, F.; BIASI, L. A. Época de coleta e ácido indolbutírico no enraizamento de miniestacas de pitangueira. Semina: Ciências Agrárias, v. 36, n. 5, p. 2055-3068, 2015. Disponível em: <http://dx.doi.org/10.5433/16790359.2015v36n5p3055>. doi: 10.5433/1679-0359.2015v36n5p3055

PICOLOTTO, L.; VIGNOLO, G. K.; PEREIRA, I. S.; GONCALVES, M. A.; ANTUNES, L. E. C. Enraizamento de estacas de amoreira-preta em função da adubação nitrogenada na planta matriz. Revista Ceres, v. 62, n. 3, p. 294-300, 2015. Disponível em: <http://dx.doi.org/10.1590/0034-737X201562030009>. doi: 10.1590/0034-737X201562030009

PIRES, P.; WENDLING, I.; AUER, C.; BRONDANI, G. Sazonalidade e soluções nutritivas na miniestaquia de Araucaria angustifólia (Bertol.) kuntze. Revista Árvore, v. 39, n. 2, p. 283-293, 2015. Disponível em: <http://dx.doi.org/10.1590/010067622015000200008>. doi: 10.1590/0100-67622015000200008

ROCHA, J. H. T.; PIETRO, M. R.; BORELLI, K.; BACKES, C.; NEVES, M. B. Produção e desenvolvimento de mudas de eucalipto em função de doses de fósforo. 
Cerne, v. 19, n. 4, 2013. Disponível em: <http://dx.doi.org/10.1590/S010477602013000400002>. doi: 10.1590/S0104-77602013000400002

SANTOS, A. P.; XAVIER, A.; OLIVEIRA, M. L.; REIS, G. G. Efeito da estaquia, miniestaquia, microestaquia e micropropagação no desempenho silvicultural de clones de Eucalyptus grandis. Scientia forestalis, n. 68, p. 29 - 38, 2005.

SANTOS, V. A. H. F.; GARCIA, M. N.; DEMARTINI, W. F. B.; ROSALINO, W.; MANGABEIRA, F. D. C.; SANTOS, J. P. Influência do período pós-estabelecimento de minijardim clonal sobre o enraizamento de miniestacas de eucalipto. Scientific Electronic Archives, v. 5, p. 68-71, 2014.

SOUZA JUNIOR, L.; WENDLING, I. Propagação vegetativa de Eucalyptus dunnii via miniestaquia de material juvenil. Boletim de Pesquisa Florestal, n. 46, p. 21-30, 2003.

SOUZA, C. C.; XAVIER, A.; LEITE, F. P.; SANTANA, R. C.; LEITE, H. G. Padrões de miniestacas e sazonalidade na produção de mudas clonais de Eucalyptus grandis Hill x E. urophylla S. T. Black. Revista árvore, v. 37, n. 1, p. $67-77,2013$. Disponível em: <http://dx.doi.org/10.1590/S0100-67622013000100008>. doi: 10.1590/S0100-67622013000100008

TAKATA, W. H. S.; SILVA, E. G.; BARDIVIESSO, D. M. Enraizamento de estacas de Duranta repens Linn "Aurea" em função de doses de IBA. Revista científica eletrônica de Agronomia, v. 21, n. 1, p. 1-9, 2012.

TIMM, C. R. F.; SCHUCH, M. W.; TOMAZ, Z. F. P.; MAYER, N, M, A. Enraizamento de miniestacas a partir de ramos herbáceos de porta-enxertos de pessegueiro, em diferentes substratos. Revista Inova Ciência e Tecnologia, p. 18 - 22, n. 1, p. 18 22, 2015.

TITON, M.; XAVIER, A.; OTONI, W. C.; REIS, G. G. Efeito do AIB no enraizamento de miniestacas e microestacas de clones de Eucalyptus grandis W. Hill ex Mainden. Revista árvore, v. $27, \quad$ n. 1 , p. $1-7,2003$. Disponível em: <http://dx.doi.org/10.1590/S0100-67622003000100001>. doi: 10.1590/S010067622003000100001

VERNIER, R. M.; CARDOSO, S. B. Influência do ácido indol- butírico no enraizamento de estacas em espécies frutíferas e ornamentais. Revista eletrônica de Educação e Ciência, v. 3, n.2, p. 11-16, 2013.

VILLA, F.; PIO, R.; CHALFUN, N. N. J.; GONTIJO, T. C. A.; DUTRA, L. F. Propagação de amoreira-preta utilizando estacas lenhosas. Revista Ciência e Agrotecnologia, v. 27, n. 4, p. 829 - 834, 2003. Disponível em: <http://dx.doi.org/10.1590/S1413-70542003000400013>. doi: 10.1590/S141370542003000400013

XAVIER, A.; WENDLING, I.; SILVA, R. L. Silvicultura clonal: Princípios e Técnicas. Viçosa: editora UFV, 2009, 272 p. 
ZANG, W.; SONG, L.; SILVA, J. A. T.; SUN, H. Effects of temperature, plant growth regulators and substrates and changes in carbohydrate content during bulblet formation by twin scale propagation in Hippeastrum vittatum 'Red lion'. Scentia Horticulturae, v. 160, n. 160, p. 230 - 237, 2013. Disponível em: <http://dx.doi.org/10.1016/j.scienta.2013.06.001>. doi:10.1016/j.scienta.2013.06.001

WENDLING, I.; XAVIER, A. Influência do ácido indolbultírico e da miniestaquia seriada no enraizamento e vigor de miniestacas de clones de Eucalyptus grandis. Revista árvore, v. 29, n. 6, p. 921 - 930, 2005. Disponível em: <http://dx.doi.org/10.1590/S0100-67622005000600011>. doi: 10.1590/S010067622005000600011 